\title{
Monocyte chemoattractant protein-1, macrophage colony stimulating factor, survivin, and tissue inhibitor of matrix metalloproteinases-2 in analysis of damage and repair related to pediatric chronic kidney injury
}

\author{
Kinga MusiałA-D,F, Danuta Zwolińska ${ }^{\mathrm{C}, \mathrm{E}, \mathrm{F}}$ \\ Department and Clinic of Pediatric Nephrology, Wroclaw Medical University, Poland \\ A - research concept and design; $\mathrm{B}$ - collection and/or assembly of data; $\mathrm{C}$ - data analysis and interpretation; \\ $D$ - writing the article; $E$ - critical revision of the article; $F$ - final approval of the article
}

Address for correspondence

Kinga Musiał

E-mail: kinga_musia@@hotmail.com

Funding sources

None declared

Conflict of interest

None declared

Received on March 22, 2020

Reviewed on May 13, 2020

Accepted on June 2, 2020

Published online on September 9, 2020

Cite as

Musiał K, Zwolińska D. Monocyte chemoattractant protein-1, macrophage colony stimulating factor, survivin, and tissue inhibitor of matrix metalloproteinases-2 in analysis of damage and repair related to pediatric chronic kidney injury. Adv Clin Exp Med. 2020;29(9):1083-1090.

doi:10.17219/acem/123350

DOI

10.17219/acem/123350

Copyright

Copyright by Author(s)

This is an article distributed under the terms of the

Creative Commons Attribution 3.0 Unported (CC BY 3.0)

(https://creativecommons.org/licenses/by/3.0/)

\begin{abstract}
Background. Kidney injury in the course of chronic kidney disease (CKD) is a consequence of aggravated cell migration, inflammation, apoptosis, and fibrosis. However, the sequence of these phenomena, as well as of the reparatory mechanisms, are not fully known. Monocyte chemoattractant protein 1 (MCP-1) and macrophage colony-stimulating factor (MCSF) trigger monocyte migration to the sites of inflammation and their transition into macrophages. Tissue inhibitor of matrix metalloproteinases-2 (TIMP-2) plays a protective role against excessive matrix remodeling, whereas survivin is known for its anti-apoptotic activity.
\end{abstract}

Objectives. To analyze the serum, urine and fractional excretion (FE) values of MCP1, MCSF, TIMP-2, and survivin in children at subsequent stages of CKD being treated conservatively, and to analyze the potential applicability of these markers in the evaluation of CKD-related renal damage and protective mechanisms against it.

Material and methods. The study group consisted of 70 children with conservatively treated CKD, stages $1-5$, and 12 controls. The serum and urine concentrations of MCP1, MCSF, TIMP-2, and survivin were assessed using enzyme-linked immunosorbent assay (ELISA). The FE of these parameters in the urine was also assessed.

Results. The serum values of all parameters were significantly elevated at CKD stage 1 compared to the controls. The urinary concentrations of MCP-1 and MCSF (stages 1-2) rose earlier than TIMP-2 and survivin (stage 4) concentrations. The FE values started increasing at CKD stage 3 (MCP-1) or stage 4 (other parameters).

Conclusions. The complex analysis of serum/urinary/fEE values of the selected parameters revealed a sequence of multifaceted CKD-related phenomena, when the migration of cells and inflammation were followed by delayed and insufficient anti-fibrotic and anti-apoptotic activity.

Key words: apoptosis, chronic kidney disease, fibrosis, inflammation, urinary fractional excretion 


\section{Introduction}

Renal interstitial fibrosis is the final step in the progression of chronic kidney disease (CKD), irrespective of its origin, and confirms its irreversibility. ${ }^{1}$ It is a consequence of an imbalance between tissue repair and damage. ${ }^{2}$ Tubular damage in particular seems to determine the renal outcome. ${ }^{3}$ Chronic kidney disease triggers both destructive and protective mechanisms in the kidney, concerning immunocompetent cell activity, inflammation or apoptosis. ${ }^{2}$ However, the sequence of interactions between injury and regeneration and pro- and anti- inflammatory/apoptotic/ fibrotic stimuli is unknown.

Monocyte chemoattractant protein 1 (MCP-1) and macrophage colony stimulating factor (MCSF) are engaged in the early phase of injury: immunocompetent cell migration to the sites of inflammation. The chemotactic activity of MCP-1 controls migration of monocytes, whereas the MCSF guidance triggers their transition into macrophages in situ. ${ }^{4}$ The localization of MCP-1 in renal proximal tubules, as well as its pro-inflammatory and pro-fibrotic activity, have been proven in animal models. ${ }^{5,6}$ Studies in children with CKD focused on the MCP1 gene (MCP-12518 A/G polymorphism) in focal segmental glomerulosclerosis and on connections between plasma MCP-1 and lipid metabolism in CKD. ${ }^{7,8}$ Our previous study revealed increased serum concentrations of MCP-1 in children with mild stages of CKD compared to those at the advanced stages. ${ }^{9}$ However, the role of MCP-1 as a marker of progressive kidney injury in the course of CKD is unknown.

So far, MCSF has been analyzed mainly as a marker of atherosclerosis in adults on chronic hemodialysis. ${ }^{10,11}$ Data concerning the role of MCSF in the pathogenesis of CKD-related damage is limited to our preliminary report on elevated serum and urine concentrations in children; this issue not been analyzed in the context of the apoptotic or fibrotic aspects of CKD progression. ${ }^{9}$

Survivin takes part in the regulation of cell division, proliferation and apoptosis. ${ }^{12}$ Its ability to inhibit apoptosis was first proven in oncology, but further studies have also revealed anti-apoptotic and protective activity in response to ischemia/reperfusion injury in the course of acute kidney injury. ${ }^{13,14}$ Moreover, its location in the apical membrane of proximal tubule cells and internalization by megalin prove that it is reabsorbed from the primary urine. ${ }^{15}$ Studies in CKD patients are restricted to our previous reports on elevated survivin concentrations in children with advanced CKD. ${ }^{16}$ However, the question of whether survivin shows any protective features against chronic kidney injury remains unknown.

The anti-fibrotic activity of TIMP-2 and its role in the cell cycle regulation have been known for some time, but it was only recently confirmed in vitro to be located in the distal tubule cells. ${ }^{17}$ Urinary TIMP-2 is an established marker of acute kidney injury, but its potential role in assessing renal damage in the course of CKD progression is unknown. ${ }^{18}$
Our previous observations have suggested that the fractional excretion (FE) of molecules in the urine may be added value in the analysis of tubular function in children with CKD. 9,19,20

This study is the first attempt to evaluate inflammatory/fibrotic/apoptotic phenomena using the combined analysis of serum/urinary/FE values of the selected parameters throughout all stages of pediatric CKD. Our aim was to analyze the usefulness of MCP-1, MCSF, survivin, and TIMP-2 in the assessment of CKD-related mechanisms of kidney injury in children, including inflammation, apoptosis and fibrosis, as well as the protective mechanisms against them.

\section{Material and methods}

\section{Study design and settings}

This is a retrospective cross-sectional study, carried out from 2016 to 2018 on 70 children with CKD and 12 controls. The CKD patients were divided into 5 groups according to CKD stage (patient flow is shown in in Fig. 1). Table 1 shows the basic demographic and biochemical data. The control group consisted of children with monosymptomatic nocturnal enuresis and normal kidney function.

The enrollment criteria for CKD children were age between 2 and 18 years and at least three-month follow-up since the diagnosis of CKD. The exclusion criteria consisted of comorbidities (diabetes, malignancy, allergy, systemic disease or primary glomerulopathy, vasculitis, peripheral vascular disease, and obesity), smoking, immunosuppression or corticosteroid therapy, current infection, or antibiotic therapy.

The causative factors for CKD were obstructive uropathy (23 patients), hypo-/dysplastic kidneys (15), reflux nephropathy (14), polycystic kidney disease (4), other genetic disorders (5), acute kidney injury (4), and unknown factors (5). Hypertension was diagnosed according to the criteria of the European Society of Hypertension in children and adolescents. ${ }^{21}$

Informed consent was obtained from the patients and their parents, if necessary. The research project was approved by the Wroclaw Medical University (Wrocław, Poland) ethics committee, in accordance with the Declaration of Helsinki.

\section{Methods}

Blood samples were drawn after an overnight fast from the peripheral veins. Samples were clotted for $30 \mathrm{~min}$ and centrifuged at room temperature for $10 \mathrm{~min}$; the serum was then stored at $-80^{\circ} \mathrm{C}$ until assayed. Urine was collected aseptically from the first morning sample, centrifuged at room temperature for $10 \mathrm{~min}$ and stored at $-80^{\circ} \mathrm{C}$ until assayed.

The serum and urine concentrations of MCP-1, MCSF, survivin, and TIMP-2 were evaluated using commercially available enzyme-linked immunosorbent assay (ELISA) kits (MCP-1 - reagent kit DCP00; MCSF - reagent kit DMC00B; 


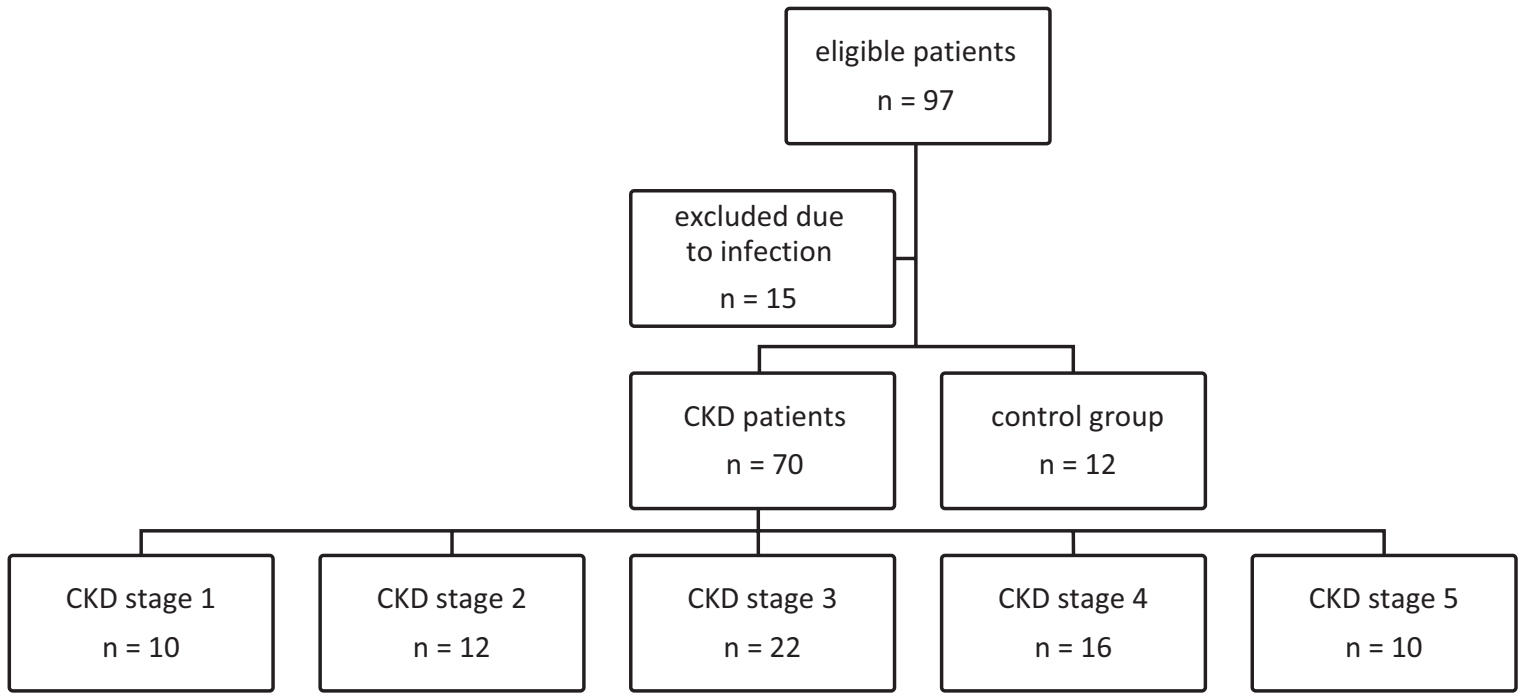

Fig. 1. Patient flow diagram

Table 1. Basic demographic and clinical data

\begin{tabular}{|c|c|c|c|c|c|c|}
\hline \multirow{2}{*}{$\begin{array}{c}\text { Parameter } \\
\text { (median value (lower- } \\
\text { upper quartile)) }\end{array}$} & \multicolumn{6}{|c|}{ Study groups } \\
\hline & $\begin{array}{l}\text { Control group } \\
\qquad(n=12)\end{array}$ & $\begin{array}{l}\text { CKD } 1 \\
(n=10)\end{array}$ & $\begin{array}{l}\text { CKD 2 } \\
(n=12)\end{array}$ & $\begin{array}{l}\text { CKD } 3 \\
(n=22)\end{array}$ & $\begin{array}{l}\text { CKD } 4 \\
(n=16)\end{array}$ & $\begin{array}{l}\text { CKD 5 } \\
(n=10)\end{array}$ \\
\hline Gender & 6 girls, 6 boys & 4 girls, 6 boys & 6 girls, 6 boys & 7 girls, 15 boys & 7 girls, 9 boys & 4 girls, 6 boys \\
\hline Age [years] & $\begin{array}{c}10.5 \\
(7.9-14.2)\end{array}$ & $\begin{array}{c}13.4 \\
(4.1-14.3)\end{array}$ & $\begin{array}{c}10.1 \\
(8.4-15.4)\end{array}$ & $\begin{array}{c}9.1 \\
(6.3-12.0)\end{array}$ & $\begin{array}{c}10.9 \\
(6.8-15.2)\end{array}$ & $\begin{array}{c}9.2 \\
(2.8-15.2)\end{array}$ \\
\hline $\begin{array}{l}\text { eGFR } \\
{\left[\mathrm{mL} / \mathrm{min} / 1.73 \mathrm{~m}^{2}\right]}\end{array}$ & $\begin{array}{c}115 \\
(94-120)\end{array}$ & $\begin{array}{c}112 \\
(106-123)\end{array}$ & $\begin{array}{l}74 a, b \\
(62-82)\end{array}$ & $\begin{array}{c}45^{\mathrm{a}, \mathrm{c}} \\
(35-52)\end{array}$ & $\begin{array}{c}23^{a, d} \\
(20-26)\end{array}$ & $\begin{array}{l}11 \mathrm{a}, \mathrm{e} \\
(9-13)\end{array}$ \\
\hline $\begin{array}{l}\text { Proteinuria } \\
{[\mathrm{mg} / \mathrm{mg} \text { creatinine }]}\end{array}$ & $\begin{array}{c}3.0 \\
(0.0-5.1)\end{array}$ & $\begin{array}{c}4.8 \\
(0.0-108.7)\end{array}$ & $\begin{array}{c}31.6^{\mathrm{a}} \\
(0.0-482.0)\end{array}$ & $\begin{array}{c}31.7^{\mathrm{a}} \\
(0.0-351.5)\end{array}$ & $\begin{array}{c}79.4^{\mathrm{a}, \mathrm{d}} \\
(10.7-718.4)\end{array}$ & $\begin{array}{c}197.3^{\mathrm{a}, \mathrm{e}} \\
(54.4-2,119.8)\end{array}$ \\
\hline
\end{tabular}

Mann-Whitney U test: ${ }^{a} p<0.001$ CKD compared to control group; ${ }^{b} p<0.001$ CKD stage 2 compared to stage $1 ;{ }^{c} p<0.001$ CKD stage 3 compared to stage $2 ;{ }^{d} p<0.001$ CKD stage 4 compared to stage $3 ;{ }^{e} p<0.001$ CKD stage 5 compared to stage 4. eGFR - estimated glomerular filtration rate; CKD - chronic kidney disease.

survivin - reagent kit DSV00; and TIMP-2 - reagent kit DTM200; all from R\&D Systems, Minneapolis, USA). The measurements were performed according to the manufacturer's instructions, and the results were calculated by reference to standard curves. The intra-assay and interassay coefficients of variation $(\% \mathrm{CV})$ for the examined parameters did not exceed $8.2 \%$ and $9.3 \%$, respectively.

Serum and urine markers were measured with automated routine diagnostic tests: creatinine OSR61204 reagent using Beckman Coulter AU2700 analyzer (Beckman Coulter, Brea, USA) and proteinuria using turbidimetry. Estimated glomerular filtration rate (eGFR) was calculated according to Schwartz's formula. ${ }^{22}$ The urinary concentrations of the selected parameters were normalized for urinary creatinine values. The FE of the parameters was calculated based on the following formula:

$$
\begin{aligned}
\mathrm{FE}= & \frac{([\text { urine parameter concentration }] \times}{([\text { serum creatinine concentration }])} \\
& \times[\text { urine creatinine concentration }])
\end{aligned}
$$

\section{Statistical analysis}

The results are expressed as median values and interquartile ranges (IQR). The null hypothesis of normality of distribution of the analyzed variables was rejected using a Shapiro-Wilk test. Thus, the comparisons and correlations between the subgroups were evaluated using nonparametric tests (Kruskal-Wallis test, Mann-Whitney U test and Spearman's correlation coefficient). The statistically significant correlations in the whole group were then analyzed using linear regression analysis. The linear regression equations were calculated according to the following formula:

$$
y=\beta x+a,
$$

where $y$ is the dependent variable, $\beta$ is the regression coefficient, $\mathrm{x}$ is the independent variable, and $\mathrm{a}$ is a constant). Statistical analysis was performed using the STATISTICA v. 13.0 software package (StatSoft, Inc., Tulsa, USA). A p-value $<0.05$ was considered significant. 


\section{Results}

\section{Serum MCP-1, MCSF, survivin, and TIMP-2 concentrations}

The serum concentrations of all examined parameters were significantly higher in comparison with the controls, even from the earliest stages of CKD (Fig. 2-5). The steep rise in CKD stage 1 was observed in the case of MCP-1, MCSF and TIMP-2, where the concentrations increased more than threefold, whereas those of survivin only by $30 \%$ (Fig. 2-5). However, MCSF and survivin values showed a gradual increase along with the progression of CKD (Fig. 3-4), whereas in the case of MCP-1, a short plateau phase appeared between CKD stages 2 and 3 (Fig. 2). The TIMP-2 concentrations rose at CKD stage 1 and then stabilized until stage 4 , when they peaked again until stage 5 (Fig. 5 ).

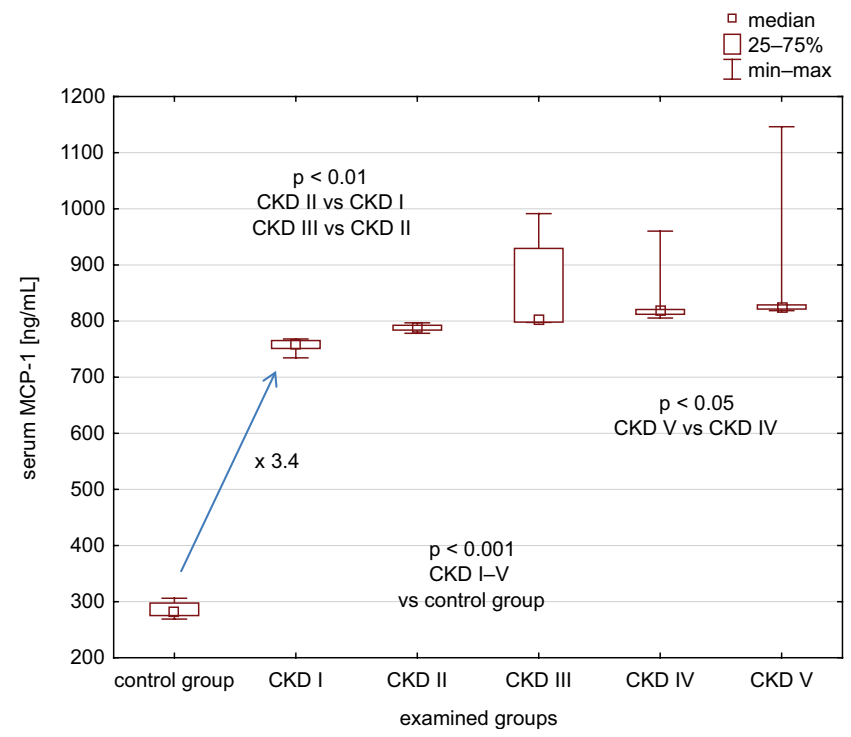

Fig. 2. Serum MCP-1 concentrations in children with CKD and controls

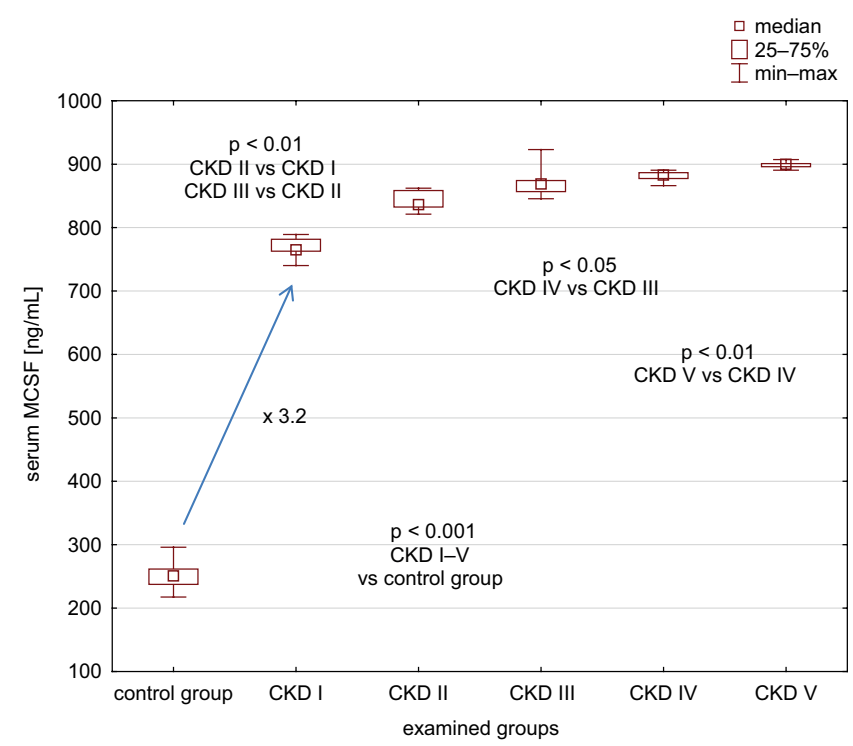

Fig. 3. Serum MCSF concentrations in children with CKD and controls

\section{Urine MCP-1, MCSF, survivin, and TIMP-2 concentrations}

The urinary concentrations of the selected parameters, normalized for creatinine in urine, behaved differently. The MCP-1 values were elevated in comparison with the controls even at CKD stage 1 ; they rose until stage 2 and then remained stable until stage 5 (Table 2). The MCSF values grew in relation to the control group in CKD stage 2 and also remained unchanged until stage 5 (Table 2). Survivin and TIMP-2 augmentation reached the level of statistical significance no sooner than at stage 4 and remained unchanged in stage 5 (Table 2). All urinary values were significantly higher in CKD stage 2 than in stage 1.

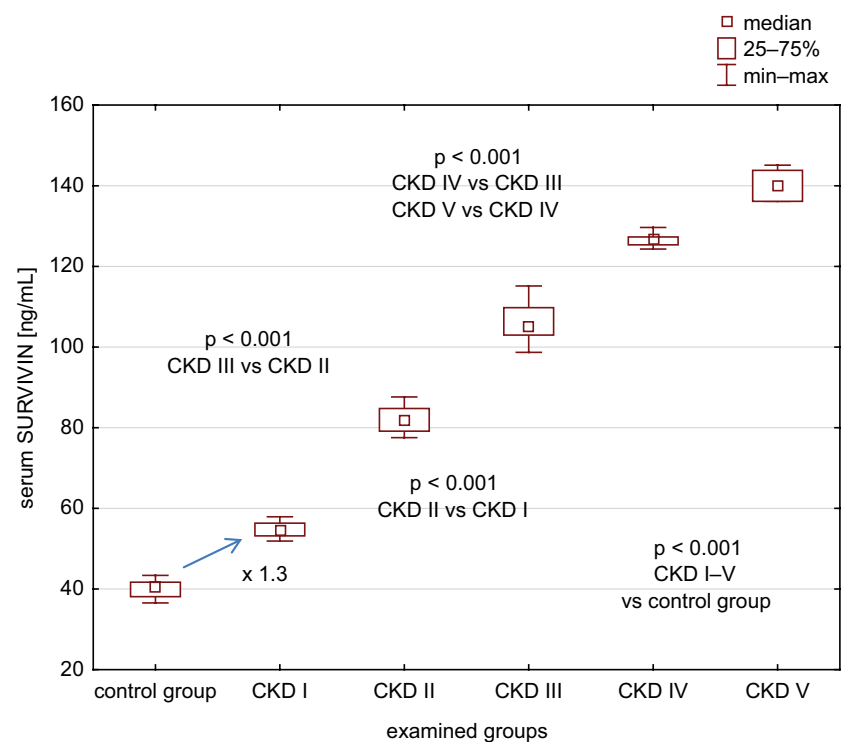

Fig. 4. Serum survivin concentrations in children with CKD and controls

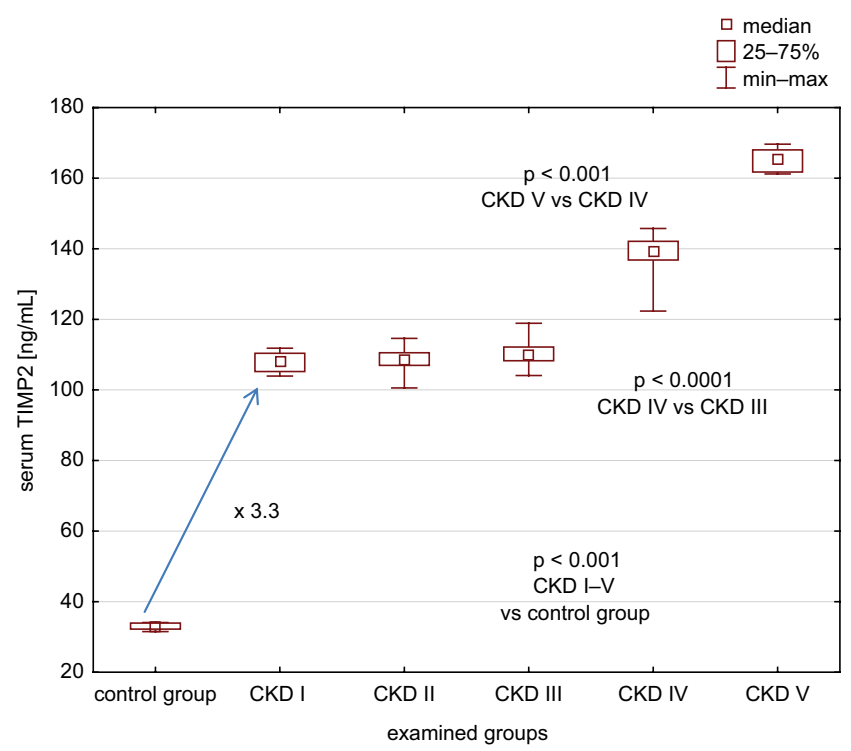

Fig. 5. Serum TIMP-2 concentrations in children with CKD and controls 
Table 2. Urinary (u) values of the parameters under study

\begin{tabular}{|c|c|c|c|c|c|c|}
\hline Parameter & $\begin{array}{l}\text { Control group } \\
(n=12)\end{array}$ & $\begin{array}{l}\text { CKD stage } 1 \\
\quad(n=10)\end{array}$ & $\begin{array}{l}\text { CKD stage } 2 \\
(\mathrm{n}=12)\end{array}$ & $\begin{array}{c}\text { CKD stage } 3 \\
(\mathrm{n}=22)\end{array}$ & $\begin{array}{l}\text { CKD stage } 4 \\
(n=16)\end{array}$ & $\begin{array}{l}\text { CKD stage } 5 \\
(\mathrm{n}=10)\end{array}$ \\
\hline $\begin{array}{l}\text { u MCP-1 } \\
\text { [ng/mg creatinine] }\end{array}$ & $\begin{array}{c}2.38 \\
(2.26-2.99)\end{array}$ & $\begin{array}{c}5.11^{\mathrm{a}} \\
(3.58-6.88)\end{array}$ & $\begin{array}{c}8.43^{a, b} \\
(4.89-11.45)\end{array}$ & $\begin{array}{c}12.14^{\mathrm{a}} \\
(6.51-16.64)\end{array}$ & $\begin{array}{c}9.73^{a} \\
(7.33-10.42)\end{array}$ & $\begin{array}{c}11.39^{a} \\
(8.17-12.28)\end{array}$ \\
\hline $\begin{array}{l}\text { u MCSF } \\
\text { [ng/mg creatinine] }\end{array}$ & $\begin{array}{c}27.65 \\
(26.82-32.08)\end{array}$ & $\begin{array}{c}41.46 \\
(30.91-59.17)\end{array}$ & $\begin{array}{c}74.92^{a, b} \\
(40.89-98.87)\end{array}$ & $\begin{array}{c}96.63 \\
(58.47-142.28)\end{array}$ & $\begin{array}{c}86.72^{a} \\
(62.43-90.86)\end{array}$ & $\begin{array}{c}88.92^{a} \\
(64.31-95.98)\end{array}$ \\
\hline $\begin{array}{l}\text { u survivin } \\
\text { [ng/mg creatinine] }\end{array}$ & $\begin{array}{c}0.55 \\
(0.53-0.63)\end{array}$ & $\begin{array}{c}0.42 \\
(0.41-0.77)\end{array}$ & $\begin{array}{c}0.94^{\mathrm{b}} \\
(0.49-1.21)\end{array}$ & $\begin{array}{c}0.95 \\
(0.56-1.07)\end{array}$ & $\begin{array}{c}1.11^{\mathrm{a}} \\
(0.88-1.20)\end{array}$ & $\begin{array}{c}1.28^{\mathrm{a}} \\
(0.60-2.87)\end{array}$ \\
\hline $\begin{array}{l}\text { uTIMP-2 } \\
\text { [ng/mg creatinine] }\end{array}$ & $\begin{array}{c}0.13 \\
(0.11-0.14)\end{array}$ & $\begin{array}{c}0.11 \\
(0.10-0.21)\end{array}$ & $\begin{array}{c}0.24^{b} \\
(0.13-0.31)\end{array}$ & $\begin{array}{c}0.23 \\
(0.14-0.27)\end{array}$ & $\begin{array}{c}0.34^{\mathrm{a}} \\
(0.27-0.39)\end{array}$ & $\begin{array}{c}0.44^{\mathrm{a}} \\
(0.21-0.99)\end{array}$ \\
\hline
\end{tabular}

Mann-Whitney U test: ${ }^{\mathrm{a}} \mathrm{p}<0.001$ CKD compared to control group; ${ }^{\mathrm{b}} \mathrm{p}<0.001$ CKD stage 2 compared to stage 1 . CKD - chronic kidney disease; MCP-1 - monocyte chemoattractant protein 1; MCSF - macrophage colony-stimulating factor; TIMP-2 - tissue inhibitor of matrix metalloproteinases-2.

\section{The values of urinary FE of MCP-1, MCSF, survivin, and TIMP-2}

The FE values of MCSF, survivin and TIMP-2 were significantly lower than those of the control group at CKD stage 1, whereas the FE values of MCP-1 remained comparable to those in controls (Table 3 ). In CKD stage 2, none of the FE values differed from those in the control group. Contrarily, the FE of MCP-1 was significantly different than that of the control group at CKD stage 3, whereas the FE of the other parameters reached that threshold at CKD stage 4 ( Table 3). The values of FE of survivin were the only ones that continued growing from stage 4 until stage 5 (Table 3 ).

Of note, the FE of MCSF presented values above 1\% in both the controls and in all CKD patients. The FE of MCP-1 and survivin surpassed $1 \%$ at CKD stage 2 , while the FE values of TIMP-2 did so at stage 4 .

\section{Correlations}

Correlation analysis within subgroups revealed no significant results. In the whole group of CKD children, the serum concentrations of the analyzed parameters correlated positively with each other (Table 4), with the exception of MCP-1 and the values for survivin and TIMP-2. Additionally, serum survivin and TIMP-2 correlated negatively with eGFR and positively with the corresponding urinary values and proteinuria (Table 4). The urinary values of all markers correlated with proteinuria. Survivin and TIMP-2 urine values also correlated negatively with eGFR (Table 4). The FE values of all markers correlated with proteinuria.

However, on linear regression analysis, only serum survivin could predict eGFR $\left(R^{2}=0.86 ; p<0.0000001\right)$, whereas FE of survivin $\left(R^{2}=0.69 ; \mathrm{p}<0.000001\right)$ and $\mathrm{FE}$ of TIMP-2 $\left(\mathrm{R}^{2}=0.73 ; \mathrm{p}<0.000001\right)$ were good predictors of proteinuria.

\section{Discussion}

Our study revealed the various patterns of elevated serum and urinary values of MCP-1, MCSF, survivin, and TIMP-2, as well as changes in the urinary FE of these parameters, in pediatric patients with CKD compared to a control group.

While analyzing the dynamics of the observed fluctuations, the elevation of MCP-1 concentration was the earliest (CKD stage 1) and was seen concomitantly in the serum and urine. These results were in agreement with our

Table 3. Fractional excretion values of the parameters under study

\begin{tabular}{|c|c|c|c|c|c|c|}
\hline Parameter $\quad$ Study group & $\begin{array}{l}\text { Control group } \\
\quad(n=12)\end{array}$ & $\begin{array}{l}\text { CKD stage } 1 \\
\qquad(n=10)\end{array}$ & $\begin{array}{l}\text { CKD stage } 2 \\
\quad(n=12)\end{array}$ & $\begin{array}{l}\text { CKD stage } 3 \\
(n=22)\end{array}$ & $\begin{array}{l}\text { CKD stage } 4 \\
(n=16)\end{array}$ & $\begin{array}{l}\text { CKD stage } 5 \\
\quad(n=10)\end{array}$ \\
\hline FE MCP-1 [\%] & $\begin{array}{c}0.59 \\
(0.65-0.87)\end{array}$ & $\begin{array}{c}0.40 \\
(0.36-0.56)\end{array}$ & $\begin{array}{c}0.69^{b} \\
(0.57-2.07)\end{array}$ & $\begin{array}{c}2.03^{\mathrm{a}} \\
(0.99-3.39)\end{array}$ & $\begin{array}{c}3.45^{\mathrm{a}} \\
(2.10-4.91)\end{array}$ & $\begin{array}{c}4.42^{\mathrm{a}} \\
(4.19-5.54)\end{array}$ \\
\hline FE MCSF [\%] & $\begin{array}{c}8.09 \\
(6.44-10.67)\end{array}$ & $\begin{array}{c}3.88^{\mathrm{a}} \\
(3.14-4.49)\end{array}$ & $\begin{array}{c}7.33^{b} \\
(4.83-17.54)\end{array}$ & $\begin{array}{c}16.33 \\
(9.29-28.19)\end{array}$ & $\begin{array}{c}28.74^{\mathrm{a}} \\
(16.89-40.28)\end{array}$ & $\begin{array}{c}32.47^{\mathrm{a}} \\
(29.90-40.19)\end{array}$ \\
\hline FE survivin [\%] & $\begin{array}{c}0.96 \\
(0.76-1.20)\end{array}$ & $\begin{array}{c}0.64^{\mathrm{a}} \\
(0.55-0.79)\end{array}$ & $\begin{array}{c}0.79 \\
(0.67-2.41)\end{array}$ & $\begin{array}{c}1.14 \\
(0.73-2.95)\end{array}$ & $\begin{array}{c}2.79 \mathrm{a}, \mathrm{d} \\
(1.67-3.84)\end{array}$ & $\begin{array}{c}4.26^{\mathrm{a}, \mathrm{e}} \\
(2.95-14.55)\end{array}$ \\
\hline FE TIMP-2 [\%] & $\begin{array}{c}0.24 \\
(0.22-0.36)\end{array}$ & $\begin{array}{c}0.08^{\mathrm{a}} \\
(0.08-0.11)\end{array}$ & $\begin{array}{c}0.16^{b} \\
(0.14-0.48)\end{array}$ & $\begin{array}{c}0.28 \\
(0.18-0.69)\end{array}$ & $\begin{array}{c}0.87^{\mathrm{a}, \mathrm{d}} \\
(0.47-1.02)\end{array}$ & $\begin{array}{c}1.20^{\mathrm{a}} \\
(0.87-4.30)\end{array}$ \\
\hline
\end{tabular}

Mann-Whitney U test: ${ }^{a} p<0.001$ CKD compared to control group; ${ }^{b} p<0.001$ CKD stage 2 compared to stage $1 ;{ }^{c} p<0.001$ CKD stage 3 compared to stage $2 ;{ }^{d} \mathrm{p}<0.001$ CKD stage 4 compared to stage $3 ;{ }^{\mathrm{e}} \mathrm{p}<0.001$ CKD stage 5 compared to stage 4 . CKD - chronic kidney disease; FE - fractional excretion; MCP-1 - monocyte chemoattractant protein 1; MCSF - macrophage colony-stimulating factor; TIMP-2 - tissue inhibitor of matrix metalloproteinases-2. 
Table 4. Significant correlations between parameters

\begin{tabular}{|c|c|c|c|c|}
\hline Parameter & $\begin{array}{c}\text { u survivin } \\
\text { [ng/mg creatinine] }\end{array}$ & $\begin{array}{c}\text { u TIMP-2 } \\
\text { [ng/mg creatinine] }\end{array}$ & $\begin{array}{c}\text { eGFR } \\
{\left[\mathrm{mL} / \mathrm{min} / 1.73 \mathrm{~m}^{2}\right]}\end{array}$ & $\begin{array}{l}\text { Proteinuria } \\
\text { [g/dL] }\end{array}$ \\
\hline s survivin [ng/mL] & $\begin{array}{c}r=0.40 \\
p=0.0009\end{array}$ & $\begin{array}{c}r=0.47 \\
p=0.00008\end{array}$ & $\begin{array}{c}r=-0.91 \\
p=0.0000001\end{array}$ & $\begin{array}{l}r=0.42 \\
p=0.003\end{array}$ \\
\hline s TIMP-2 [ng/mL] & $\begin{array}{l}r=0.33 \\
p=0.007\end{array}$ & $\begin{array}{c}r=0.42 \\
p=0.0005\end{array}$ & $\begin{array}{c}r=-0.77 \\
p=0.0000001\end{array}$ & $\begin{array}{c}r=0.52 \\
p=0.0002\end{array}$ \\
\hline FE survivin [\%] & $\begin{array}{c}r=0.47 \\
p=0.00007\end{array}$ & $\begin{array}{c}r=0.55 \\
p=0.000002\end{array}$ & $\begin{array}{c}r=-0.66 \\
p=0.0000001\end{array}$ & $\begin{array}{c}r=0.69 \\
p=0.0000001\end{array}$ \\
\hline FE TIMP-2 [\%] & $\begin{array}{c}r=0.60 \\
p=0.0000001\end{array}$ & $\begin{array}{c}r=0.68 \\
p=0.0000001\end{array}$ & $\begin{array}{c}r=-0.76 \\
p=0.0000001\end{array}$ & $\begin{array}{c}r=0.69 \\
p=0.0000001\end{array}$ \\
\hline $\mathrm{eGFR}\left[\mathrm{mL} / \mathrm{min} / 1.73 \mathrm{~m}^{2}\right]$ & $\begin{array}{l}r=-0.35 \\
p=0.005\end{array}$ & $\begin{array}{l}r=-0.42 \\
p=0.0005\end{array}$ & --- & $\begin{array}{l}r=-0.46 \\
p=0.001\end{array}$ \\
\hline Proteinuria [g/dL] & $\begin{array}{c}r=0.56 \\
p=0.00004\end{array}$ & $\begin{array}{c}r=0.61 \\
p=0.000005\end{array}$ & $\begin{array}{l}r=-0.46 \\
p=0.001\end{array}$ & --- \\
\hline
\end{tabular}

eGFR - estimated glomerular filtration rate; FE - fractional excretion; MCP-1 - monocyte chemoattractant protein 1; MCSF - macrophage colonystimulating factor; TIMP-2 - tissue inhibitor of matrix metalloproteinases-2; $s$ - serum; $u$ - urinary.

previous observations differentiating between mild and advanced CKD. ${ }^{9}$ Similarly, Vianna et al. ${ }^{8}$ described elevated plasma MCP-1 levels in children with CKD.

The MCP-1 is a low-molecular-weight protein, freely filtered through the glomeruli, and its early rise in urine might be a simple consequence of increased serum concentration. However, neither serum nor urinary MCP-1 correlated with eGFR, so together with the location of MCP-1 in the proximal tubules, these facts may suggest that this molecule is secreted in situ into the urine. Another argument for this hypothesis is the correlation between MCP-1 expression and monocyte infiltration in the kidneys. ${ }^{23}$ The latter may also explain the plateau phase of MCP-1 urinary values prior to CKD stage 5, when MCP-1-dependent monocyte migration is followed by their MCSF-dependent transition into macrophages.

The clarification of the abovementioned doubts came with the analysis of FE values. First, they had surpassed $1 \%$ by CKD stage 2 , signaling the commencement of tubular dysfunction. This observation was concordant with our previous results concerning FE. ${ }^{20}$ Then, the FE values of MCP-1 were higher compared to the controls at stage 3, confirming the damage of tubular structure. Interestingly, this rise was followed by the plateau phase until stage 5 . Thus, the FE rise followed the elevation in urinary MCP-1 and was probably a response to the increased serum concentration and net filtration through the glomeruli. As a consequence, serum concentration remained stable until CKD stage 4 . A further increase could not be balanced by the compensatory overactivity of the proximal tubules, already damaged in the course of CKD. Thus, the complex analysis of serum, urinary and FE values of MCP-1 suggested early migratory and inflammatory overactivity aimed at adjusting tubular function to new conditions, until irreversible tubular damage. Correlation of MCP-1 FE with proteinuria would be of added value in the assessment of the early and complex features of tubular damage in the course of CKD.
Not surprisingly, the MCSF serum elevation in CKD stage 2 followed that of MCP-1 in CKD stage 1 , likely depicting the transition of monocytes into macrophages that comes after monocyte migration. Likewise, the lack of correlation between eGFR and serum/urinary MCSF could suggest a CKD-triggered systemic and kidney overproduction of MCSF. Moreover, urinary MCSF concentrations (before correction for urine creatinine) were significantly higher than those in the serum of both the controls and the CKD patients, and this finding was specific to MCSF. Thus, MCSF in situ renal production, aggravated by CKD conditions, was a probable explanation.

The FE MCSF values above $1 \%$ in both the controls and the children with CKD seemed to confirm the intra-renal source of MCSF production. Moreover, FE values diminished significantly in CKD stage 1, suggesting early functional response of proximal tubules to increased serum MCSF. However, this mechanism turned out insufficient in advanced CKD, when FE became higher than in controls, most likely due to the tubular damage and subsequent aggravated leakage of MCSF with urine. Of note, MCSF FE correlated with proteinuria, making this parameter another useful tool for the analysis of tubular damage in CKD patients. Moreover, the assessment of serum, urinary and MCSF FE, confronted to corresponding serum, urinary and FE values of MCP-1, suggested the sequence of inflammatory and migratory activities during the early stages of CKD.

The early rise of survivin in the serum and its negative correlation with eGFR values could suggest an accumulation of the molecule. Moreover, serum survivin was the only predictor of eGFR. Like MCP-1 and MCSF, it is a protein that freely filters through the glomeruli. However, its serum concentration in CKD stage 1 only increased by $30 \%$, whereas the elevation of the abovementioned chemokines under similar conditions was threefold. Thus, this moderate elevation seemed to be independent of additional triggers, like inflammatory factors, since survivin has shown no correlation with MCP-1. 
Further elevation of serum survivin in the course of CKD progression was similar to our previous observations. ${ }^{19}$ This gradual and significant rise, stage by stage, was another argument for the molecule accumulation along with eGFR decrease. Surprisingly, it had no influence on urinary survivin, which became elevated compared to the controls no sooner than in CKD stage 4. This late increase of urinary survivin, in accordance with our previous study ${ }^{16}$ and together with its correlation with eGFR, could be explained by the filtration of this molecule through the damaged tubules rather than by in situ generation. It suggests a delayed anti-apoptotic reaction in relation to pro-inflammatory MCP-1 and MCSF overactivity.

The FE values of survivin were lower in CKD stage 1 , mimicking the MCSF FE behavior and pointing at the probable adjustment of tubular function to the increased survivin content in the serum. However, they crossed the threshold of $1 \%$ at CKD stage 2, confirming the early tubular dysfunction. The lack of elevation above the control values before CKD stage 4 is another sign of the inefficient reaction against excessive molecule loss through the urine.

Finally, serum and urinary survivin correlated with proteinuria, and the FE values were able to predict it, suggesting their usefulness in the assessment of structural changes to the renal parenchyma, which are responsible for kidney injury.

An early threefold rise in the serum TIMP-2 levels of children with CKD stage 1 was followed by a plateau phase until CKD stage 3 and a further rise until stage 5 . This pattern was specific to only this molecule. The negative correlation between TIMP-2 and eGFR would suggest accumulation, whereas the plateau phase concurring with a decrease in eGFR would suggest concomitant systemic generation. Indeed, TIMP-2 acts in concert with MMP-2 activity, starting early in the course of CKD. ${ }^{24}$ Therefore, this elevation could be triggered by MMP-2 overactivity, already perceptible at CKD stage $1 .^{24}$

As is the case with survivin, the early stages of CKD did not demonstrate an increased net content of TIMP-2 in the urine. Thus, there was a probable mechanism protecting against excessive loss of TIMP-2 through the urine and keeping the serum levels in balance until CKD stage 3 . The decrease in the FE values of TIMP-2 in CKD stage 1, which were also observed in MCSF and survivin, would suggest the increased tubular reabsorption of TIMP-2. However, presence of the latter in the proximal tubules is negligible. Instead, TIMP-2 expression and secretion is strictly connected with the distal tubules. ${ }^{17}$ Thus, could the probable mechanism be absorption in the proximal tubules and secretion by the distal tubules? This hypothesis requires verification in experimental studies.

Irrespective of the background, the process seemed effective until CKD stage 4, when the serum, urinary and FE values of TIMP-2 increased concomitantly, ending the preceding plateau period. The late urinary increase, parallel to that of survivin, could also be the sign of anti-fibrotic protective reaction, distant in time from pro-inflammatory and migratory triggers.

As in the case of survivin, serum, urinary and FE values of TIMP-2 correlated with proteinuria, adding to their role as markers of tubular damage in pediatric CKD.

In summary, the multifaceted evaluation of serum, urine and FE values of the examined parameters enabled a detailed analysis of CKD-related kidney injury stage by stage, suggesting the sequence of cell migration, inflammation and fibrosis in light of the progressing tubular damage.

Finally, we have to acknowledge the limitations of our study. Due to the lack of comparative data and reference values for the majority of the parameters under study, conclusions must be drawn cautiously. There is also a possibility of potential bias, caused by the relatively small study group and the transverse design. However, both the number of analyzed patients and the study design were adjusted to the overall size of the pediatric population with CKD.

\section{Conclusions}

Serum, urinary and FE values of MCP-1, MCSF, survivin, and TIMP-2 may become a useful tool in the complex assessment of CKD-related kidney injury, covering cell migration, inflammation, apoptosis, and fibrosis. The MCP-1 and MCSF FE values could serve as early markers of migration and inflammation, concomitant with tubular overactivity. The FE values of survivin and TIMP-2 demonstrate the late adjustment of protective anti-apoptotic and antifibrotic mechanisms, as they appear once tubular damage is already complete.

\section{ORCID iDs}

Kinga Musiał (D) https://orcid.org/0000-0002-9000-7585 Danuta Zwolińska (D) https://orcid.org/0000-0002-6714-3992

\section{References}

1. Guiteras R, Flaquer M, Cruzado JM. Macrophage in chronic kidney disease. Clin Kidney J. 2016;9(6):765-771.

2. Laurent $P$, Jolivel $V$, Manicki $P$, et al. Immune-mediated repair: A matter of plasticity. Front Immunol. 2017;8:454. doi:10.3389/fimmu.2017. 00454

3. Takaori K, Nakamura J, Yamamoto S, et al. Severity and frequency of proximal tubule injury determines renal prognosis. J Am Soc Nephrol. 2016;27(8):2393-2406.

4. Meng XM, Tang PMK, Li J, Lan HY. Macrophage phenotype in kidney injury and repair. Kidney Dis (Basel). 2015;1(2):138-146.

5. Ma W, Tao L, Wang $X$, et al. Sorafenib inhibits renal fibrosis induced by unilateral ureteral obstruction via inhibition of macrophage infiltration. Cell Physiol Biochem. 2016;39(5):1837-1849.

6. Lai KN, Leung JCK, Chan LYY, Guo H, Tang SCW. Interaction between proximal tubular cells and infiltrating monocytes/T cells in the proteinuric state. Kidney Int. 2007;71(6):526-538.

7. Besbas N, Kalyoncu M, Cil O, Ozgul RK, Bakkaloglu A, Ozaltin F. MCP1 2518 A/G polymorphism affects progression of childhood focal segmental glomerulosclerosis. Ren Fail. 2015;37(9):1435-1439.

8. Vianna HR, Soares CM, Silveira KD, et al. Cytokines in chronic kidney disease: Potential link of MCP-1 and dyslipidemia in glomerular diseases. Pediatr Nephrol. 2013;28(3):463-469. 
9. Musiał K, Bargenda A, Drożdż D, Zwolińska D. New markers of inflammation and tubular damage in children with chronic kidney disease. Dis Markers. 2017;2017:9389432.

10. Kihara T, Miyata Y, Furukawa M, et al. Predictive value of serum macrophage colony-stimulating factor for development of aortic calcification in haemodialysis patients: A 6 year longitudinal study. Nephrol Dial Transplant. 2005;20(8):1647-1652.

11. Haraguchi K, Kubo M, Saito T, et al. Serum level of macrophage colony-stimulating factor and atherosclerosis in hemodialysis patients. Nephron Clin Pract. 2006;102(1):c14-c20.

12. Ambrosini G, Adida C, Altieri DC. A novel anti-apoptosis gene, survivin, expressed in cancer and lymphoma. Nat Med. 1997;3(8):917-921.

13. Altieri DC. Survivin, versatile modulation of cell division and apoptosis in cancer. Oncogene. 2003:22(53):8581-8589.

14. Chen J, Chen JK, Conway EM, Harris RC. Survivin mediates renal proximal tubule recovery from AKI.J Am Soc Nephrol. 2013;24(12):2023-2033.

15. Jobst-Schwan T, Knaup KX, Nielsen R, et al. Renal uptake of the antiapoptotic protein survivin is mediated by megalin at the apical membrane of the proximal tubule. Am J Physiol Renal Physiol. 2013;305(5): F734-F744.

16. Bargenda A, Musiał K, Zwolińska D. Urine survivin, E-cadherin and matrix metalloproteinases as novel biomarkers in children with chronic kidney disease. Biomarkers. 2015;20(3):177-182.
17. Emlet DR, Pastor-Soler N, Marciszyn A, et al. Insulin-like growth factor binding protein 7 and tissue inhibitor of metalloproteinases-2: Differential expression and secretion in human kidney tubule cells. Am J Physiol Renal Physiol. 2017;312(2):F284-F296.

18. Koyner JL, Shaw AD, Chawla LS, et al. Tissue inhibitor metalloproteinase-2 (TIMP-2) and IGF-binding protein-7 (IGFBP7) levels are associated with adverse long-term outcomes in patients with AKI. J Am SoC Nephrol. 2015;26(7):1747-1754.

19. Bargenda A, Musiał K, Zwolińska D. Fractional excretion of survivin, EMMPRIN and MMP-7 in children with chronic kidney disease. Eur Med J. 2016;17:675-682.

20. Musiał K, Zwolińska D. Fractional excretion as a new marker of tubular damage in children with chronic kidney disease. Clin Chim Acta. 2018;480:99-106.

21. Lurbe E, Cifkova R, Kennedy Cruickshank J, et al; European Society of Hypertension. Management of high blood pressure in children and adolescents: Recommendations of the European Society of Hypertension. J Hypertens. 2009;27(9):1719-1742.

22. Schwartz GJ, Muñoz A, Schneider MF, et al. New equations to estimate GFR in children with CKD. J Am Soc Nephrol. 2009;20:629-637.

23. Rice JC, Spence JS, Yetman DL, Safirstein RL. Monocyte chemoattractant protein-1 expression correlates with monocyte infiltration in the post-ischemic kidney. Ren Fail. 2002;24(6):703-723.

24. MusiałK, Zwolińska D. Novel indicators of fibrosis-related complications in children with chronic kidney disease. Clin Chim Acta. 2014; 430:15-19. 